\title{
Oxidation of Oven-Dried Cassava Starch Using Hydrogen Peroxide and UV-C Irradiation to Improve Frying Expansion
}

\author{
Iffah Muflihati ${ }^{1 *}$, Djagal Wiseso Marseno ${ }^{2)}$, Yudi Pranoto ${ }^{2)}$
}

1) Department of Food Technology, Faculty of Engineering and Informatics, Universitas PGRI Semarang

2) Department of Food and Agricultural Product Technology, Faculty of Agricultural Technology, Universitas Gadjah Mada

*Corresponding author, email address: iffahmuflihati@upgris.ac.id

\begin{abstract}
Native cassava starch usually has low volume expansion. Some modifications were developed to change its physical and chemical characteristic, i.e. hydrogen peroxide addition and UV-C irradiation. The objectives of this study were to determine UV-C intensity, oxidation time, and concentration of hydrogen peroxide addition which resulted in the highest frying expansion of oven-dried cassava starch. Oxidation was conducted with acidification of cassava starch using $1 \%(\mathrm{w} / \mathrm{w})$ lactic acid, the addition of hydrogen peroxide, and irradiation of UV-C in a tumbler. Combination of UV-C intensity, oxidation time, and hydrogen peroxide concentration were adjusted by BoxBehnken design. Optimization of cassava starch was determined by Response Surface Methodology (RSM), with frying expansion as a main response. Oxidized cassava starch was analyzed for physical and chemical characteristics. The result of this study showed that the oxidation of cassava starch increased the frying expansion, carbonyl and carboxyl content, amylose content, solubility, and decreased the swelling power. The optimum condition of ovendried cassava starch oxidation was reached at 40 watt UV-C intensity, oxidation time 2,281 minutes, and hydrogen peroxide concentration $1 \%(\mathrm{w} / \mathrm{w})$, with the percentage of frying expansion $347,26 \%$.
\end{abstract}

Keywords: modified starch, volume expansion, UV-C intensity, oxidation time, concentration of hydrogen peroxide

\section{INTRODUCTION}

Cassava is one kind of agricultural commodities in Indonesia whose existence is abundant and potential for diversification in an effort to development. One of cassava products is cassava starch. One way to enhance the economic value of cassava is processing cassava starch. Cassava starch types that often found on the market are oven-dried cassava starch, commercial cassava starch, and sun-dried fermented cassava starch. Sour cassava starch is used in the manufacture of biscuit and "cheese bread" in which it is irreplaceable due to its characteristic flavor and functional properties, mainly those of expansion. The biscuits have high specific volumes, alveolar structure and crispness, similar to extruded snacks (Plata-Oviedo and Camargo, 1998).

Cassava starch especially oven-dried cassava starch and commercial cassava starch have low volume expansion. It can be a problem if using that kind of cassava starch in food stuff which need high volume expansion. Baking expansion analysis of cassava starch only illustrate the oxidized cassava starch when applied to baked products such as bread or bakery products. While cassava starch can be used more widely, for example for the development of products that require large volumes of the frying process, such as crackers, nuts and pilus atoms. Relatively few studies on starch oxidation by hydrogen peroxide are available in the literature.

Some modification was developed to improve volume expansion of cassava starch. Starch modification by oxidation process is one of the method to solve this problem. Chemical oxidation with an oxidizing agent and physical oxidation by UV-irradiation can improve the characteristic of oxidized cassava starch. Hydrogen peroxide is widely used as an oxidizer in the oxidation reaction because it is economical and environmentally friendly. The use of $\mathrm{H}_{2} \mathrm{O}_{2}$ in the oxidation of starch and cassava flour has been investigated by Parovuori et al. (1995), Sangseethong et al. (2010), Tavares et al. (2010), and Dias et al. (2011). Baking expansion of sour cassava starch that was oxidized with $\mathrm{H}_{2} \mathrm{O}_{2}$ was affected by the $\mathrm{H}_{2} \mathrm{O}_{2}$ concentration, $\mathrm{pH}$ and temperature of the reaction (Dias et al., 2011).

Solar ultraviolet (UV) radiation can be classified into UV-A (315-400 nm), UV-B (280-315 nm) and UV-C (100-280 nm), the short wavelengths of less than 290 $\mathrm{nm}$ undergoing significant absorption by the atmosphere at the ozone layer (Nee, 1996). Effect of UV irradiation to modify the starch has been investigated by Bertolini et al. (2000), Fiedorowicz et al. (1999), and Vatanasuchart et al. (2005). UV irradiation on the oxidative degradation of starch is affected by light intensity and length of exposure time. Previous study (Vatanasuchart et al., 2005) showed that cassava starches modified by $1 \%$ lactic acid hydrolysis and exposure to UV-C irradiation had effective baking expansion compared to UV-B irradiation.

The objectives of this study were to determine the effect of $\mathrm{UV}-\mathrm{C}$ intensity, time of oxidation and $\mathrm{H}_{2} \mathrm{O}_{2}$ concentration to the characteristics of oxidized oven cassava starch and commercial cassava starch, and to find optimum conditions of oxidation process using Response Surface Methodology. 


\section{MATERIALS AND METHODS \\ Materials}

Oven-dried cassava starch was obtained from industrial facilities in Lampung, Indonesia (PT. Sinar Pematang Mulia). Sun-dried fermented cassava starch was obtained from traditional industry in Yogyakarta, Indonesia. Chemical that was used was pro analysis.

\section{Preparation of cassava starch oxidation}

In making oxidized cassava starch, cassava starch was acidified with lactic acid $1 \%(w / w)$, addition of $\mathrm{H}_{2} \mathrm{O}_{2}(\mathrm{w} / \mathrm{w})$ then irradiated by UV-C in tumbler mixer. The moisture content of cassava starch was adjust at $20 \%$ before rotating in the tumbler. The combination parameter between the intensity of UV-C lamp, time of oxidation, and $\mathrm{H}_{2} \mathrm{O}_{2}$ concentration were adjusted with Box Behnken Design (Table 1) with frying expansion as the main response. Oxidized cassava starch was dried in cabinet dryer at $50^{\circ} \mathrm{C}$, size reduction and sieved (60 mesh). Oxidized cassava starch was analyzed for physical and chemical characteristics.

\section{Table 1}

A $2^{3}$ factorial design with three central points

\begin{tabular}{|c|c|c|c|}
\hline \multirow[t]{2}{*}{ Variables } & \multicolumn{3}{|c|}{ Level } \\
\hline & -1 & 0 & +1 \\
\hline $\mathrm{I}$ (watt) ${ }^{\mathrm{a}}$ & 20 & 40 & 60 \\
\hline $\mathrm{T}$ (minute $^{\mathrm{b}}$ & 1 & 2 & 3 \\
\hline $\mathrm{C}(\mathrm{g} / 100 \mathrm{~g})^{\mathrm{c}}$ & 1 & 2 & 3 \\
\hline
\end{tabular}

${ }^{a}$ I: intensity of UV-C lamp (watt)

${ }^{\mathrm{b}} \mathrm{T}$ : time of oxidation (minute)

${ }^{\mathrm{c}} \mathrm{C}$ : concentration of hydrogen peroxide

( $\mathrm{g} \mathrm{H}_{2} \mathrm{O}_{2} / 100$ g cassava starch, d.b.)

\section{Frying expansion}

Weighing $10 \mathrm{~g}$ of cassava starch, then retrieved 0.5 grams to gelatinization by adding $8 \mathrm{~mL}$ of boiling water into $0.5 \mathrm{~g}$ of starch, then heated until translucent. Gelatinized starch mixed with residual starch $(9.5 \mathrm{~g})$ is formed into a smooth dough. Weighing $0.5 \mathrm{~g}$ of dough, formed spheres, determined volume V1. Then the dough fried in a deep fryer with a temperature of $110^{\circ} \mathrm{C}$ initial cooking oil. After 3 minutes, the temperature was raised to $130^{\circ} \mathrm{C}$. In the 4 th minute, the temperature was lowered to $110^{\circ} \mathrm{C}$. After 8 minutes, the temperature is raised again to $150^{\circ} \mathrm{C}$ until $10^{\text {th }}$ minutes and then drained. During the process of frying, stirr continuously. Fried starch dough has a hard surface, so that the water tends to be difficult to penetrate its surface. The volume of frying expansion was measured by dipping quickly into a graduated cylinder until all parts submerged, calculated large increase in volume, recorded as V2. The percentage of frying expansion was calculated using Eq. (1)

Frying expansion $=\frac{\mathrm{V} 2-\mathrm{V} 1}{\mathrm{~V} 1} \times 100 \%$

\section{Carbonyl content}

Carbonyl content was determined as described by Smith (1967). Dry starch (4 g) was resuspended in distilled water $(100 \mathrm{~mL})$ and heated in a boiling water bath for $30 \mathrm{~min}$ with continuous stirring until completely gelatinized and then stored at $40^{\circ} \mathrm{C}$. The $\mathrm{pH}$ was adjusted to 3.2 with 0.1 $\mathrm{mol} / \mathrm{L} \mathrm{HCl}$; hydroxylamine chloride solution $(15 \mathrm{~mL})$ was then added to the solution (prepared by dissolving $25 \mathrm{~g}$ of reagent grade hydroxylamine chloride in water, adding 100 $\mathrm{mL}$ of $0.5 \mathrm{~mol} / \mathrm{L} \mathrm{NaOH}$ and bringing the final volume to $500 \mathrm{~mL}$ ). Samples were covered with plastic film and put into a $38^{\circ} \mathrm{C}$ oven for $4 \mathrm{~h}$ and rapidly titrated to $\mathrm{pH} 3.2$ with $0.1 \mathrm{~mol} / \mathrm{L} \mathrm{HCl}$. The carbonyl content was expressed as the quantity of carbonyl groups per 100 glucose units $(\mathrm{CO} / 100$ GU), as calculated by Eq. (2)

$\mathrm{CO} / 100 \mathrm{GU}=\frac{(\mathrm{Vb}-\mathrm{Vs}) \times \mathrm{M} \times 0.028 \times 100}{\mathrm{~W}}$

where $\mathrm{Vb}$ is the volume of $\mathrm{HCl}$ used for the blank $(\mathrm{mL}), \mathrm{Vs}$ is the volume of $\mathrm{HCl}$ required for the sample $(\mathrm{mL}), \mathrm{M}$ is the molarity of $\mathrm{HCl}$ and $\mathrm{W}$ is the sample weight (d.b.).

\section{Carboxyl content}

The carboxyl content was determined as previously described (Parovuori, et al., 1995). Dry starch (5 g) was resuspended in distilled water $(25 \mathrm{~mL})$, stirred for 30 minutes. Sample was centrifuged, washed with distilled water, and resuspended in $300 \mathrm{~mL}$ of distilled water. The resuspended samples were heated in a boiling waterbath with continuous stirring for 30 minutes to achieve complete gelatinization. The heated samples were then titrated to $\mathrm{pH} 8.2$ with $0.01 \mathrm{~mol} / \mathrm{L} \mathrm{NaOH}$. The carboxyl content was expressed as the quantity of carboxyl groups per 100 glucose units (COO/100 GU), as calculated by Eq. (3)

$\mathrm{COOH} / 100 \mathrm{GU}=\frac{(\mathrm{Vs}-\mathrm{Vb}) \times \mathrm{M} \times 0.045 \times 100}{\mathrm{~W}}$

Where $\mathrm{Vs}$ is the volume of $\mathrm{NaOH}$ required for the sample $(\mathrm{mL}), \mathrm{Vb}$ is the volume of $\mathrm{NaOH}$ used to test the blank $(\mathrm{mL}), \mathrm{M}$ is the molarity of $\mathrm{NaOH}$ and $\mathrm{W}$ is the weight of sample (d.b.)

\section{Amylose content}

Amylose content was determined using AOAC method Ed 14 ${ }^{\text {th }}(1984) .100 \mathrm{mg}$ sample was added with $1 \mathrm{~mL}$ ethanol $95 \%$ and $1 \mathrm{~N} \mathrm{NaOH} 9 \mathrm{~mL}$, heated 10 minutes in boiled water. After cooled, suspension diluted to $100 \mathrm{~mL}$. $5 \mathrm{~mL}$ of suspension was diluted up to $100 \mathrm{~mL}$ added with $1 \mathrm{~mL}$ acetic acid $1 \mathrm{~N}$, and $2 \mathrm{~mL}$ iodine $0,2 \%$, and diluted up to $100 \mathrm{~mL}$. The intensity of blue was measure with spectrophotometer at $\lambda=625 \mathrm{~nm}$.

\section{Swelling power}

Swelling power was determined as described by Leach (1959). The $0.1 \mathrm{~g}$ sample is heated in $10 \mathrm{~mL}$ distilled water in waterbath at $60^{\circ} \mathrm{C}$ for 30 minutes with constant mixing. The samples were centrifuged at $1600 \mathrm{rpm}$ for 15 minutes. The precipitated part was weighted and calculated using Eq. (4).

\section{Solubility}

The solubility of the starch was determined as described by Kainuma (1967). The $0.5 \mathrm{~g}$ samples are heated in 10 $\mathrm{mL}$ distilled waterbath at $60^{\circ} \mathrm{C}$ for 30 minutes without mixing. The samples were centrifuged at $1600 \mathrm{rpm}$ for 10 
minutes. $5 \mathrm{~mL}$ supernatant was separated, dried, weighted and calculated using Eq. (5).

Solubility $(\%)=\frac{\text { weight of sedimentalpaste }(\mathrm{g})}{\text { weight of the sample }(\text { d.b. })(\mathrm{g})}$

\section{RESULT AND DISCUSSION}

\section{Frying expansion}

Frying expansion is shown in Table 2. Frying expansion is the increasing percentage in the volume of starch dough when fried. Starch oxidation results showed a greater development of volume when fried. Oxidized oven dried cassava starch showed greater frying expansion than its native. The presence of high carboxyl groups will provide a great expand power (Demiate et al., 2000). Wang and Wang (2003) suggested that the increasing of specific volume is associated with the formation of carbonyl and carboxyl during the oxidation process that lead to improving hydration of the oxidized starch molecules. The increasing hydrating ability effects on the rising of starch water binding in starch molecules that would increase the internal pressure and the pressure of water evaporation during the baking or frying process. Sun-dried fermented cassava starch showed greater frying expansion than native oven-dried and commercial cassava starches. It is due to fermentation and UV-C radiation during manufacturing (Camargo et al., 1988; Plata-Oviedo and Camargo, 1998). Starch oxidation with hydrogen peroxide under alkaline and neutral condition leads to decreasing of specific volume (Dias et al., 2011). Lactic acidification together with sufficient UV energy resulted in partial depolymerization of the cassava starch molecules. Thus, when the starch paste was heated, the modified starch molecules more readily took up water molecules, resulting in a higher peak viscosity of the UV-B irradiated samples than those treated with the UV-C irradiation or hot air drying which provided too much starch depolymerization (Vatanasuchart et al., 2005).

Table 2

Frying expansion, carbonyl and carboxyl content of oven-dried cassava starch oxidized with hydrogen peroxide and UV-C irradiation

\begin{tabular}{lllllll}
\hline Treatment & $\mathrm{I}$ (watt) & $\mathrm{t}$ (minute) & $\mathrm{C}(\mathrm{g} / 100 \mathrm{~g})$ & $\begin{array}{l}\text { Frying } \\
\text { expansion }(\%)\end{array}$ & $\begin{array}{l}\text { Carbonyl } \\
\text { content } \\
\text { (CO/100 GU) }\end{array}$ & $\begin{array}{l}\text { Carboxyl } \\
\text { content } \\
\text { (COOH/100 GU }\end{array}$ \\
\hline 1 & & & & & 0.403 & 0.452 \\
2 & 20 & 1 & 2 & 166.67 & 0.406 & 0.642 \\
3 & 60 & 1 & 2 & 183.33 & 0.430 & 0.719 \\
4 & 20 & 3 & 2 & 291.67 & 0.403 & 0.515 \\
5 & 60 & 3 & 2 & 200 & 0.348 & 0.544 \\
6 & 20 & 2 & 1 & 250 & 0.354 & 0.459 \\
7 & 60 & 2 & 1 & 300 & 0.462 & 0.505 \\
8 & 20 & 2 & 3 & 266.67 & 0.630 & 0.435 \\
9 & 60 & 2 & 3 & 450 & 0.344 & 0.383 \\
10 & 40 & 1 & 1 & 275 & 0.479 & 0.514 \\
11 & 40 & 3 & 1 & 316.67 & 0.493 & 0.483 \\
12 & 40 & 1 & 3 & 283.33 & 0.540 & 0.902 \\
13 & 40 & 3 & 3 & 300 & 0.325 & 0.736 \\
14 & 40 & 2 & 2 & 308.33 & 0.325 & 0.740 \\
15 & 40 & 2 & 2 & 333.33 & 0.325 & 0.741 \\
Native cassava starch & 2 & 2 & 325 & 0.062 & 0.149 \\
Sun-dried fermented cassava starch & & 50 & 0.064 & 0.271 \\
\hline
\end{tabular}

\section{Carbonyl and carboxyl content}

Both of carbonyl and carboxyl content, which represents of total oxidation of starch, are presented in Table 2. The result shows that carbonyl and carboxyl content of oxidized cassava starch is higher than its native. Schmorak et al. (1963) suggested that the type and amount of functional groups on the starch molecules are formed depending on the $\mathrm{pH}$ of the reaction. Formation of carbonyl group will be more intense in acidic condition, however the number of carboxyl increases with the same manner as the $\mathrm{pH}$. The high number of carboxyl in this study, may occur due to the carbonyl group changed to carboxyl group. Conversion of hydroxyl groups to carbonyl takes place slowly, whereas carbonyl changes to carboxyl take place quickly (Sangseethong et al., 2010). The high carboxyl content of the modified starch could be directly related with the molecular fragmentation due to the oxidative treatment (Takizawa et al., 2004).

\section{Amylose content}

The result of amylose content is presented in Table 3 . Oxidation of oven-dried cassava starch increases amylose content of oxidized cassava starch greater than its native. An increasing of amylose content in oxidized starch was investigated by some studies (Fortuna et al., 2002). Berski et al. (2011) and Pereira et al. (2017) were reported that the variation of amylose content of oat starch might be due to a varietal differences and the method used for determination. Oxidation did not affect the amylose content of the oat starches. The oxidation level of oat starch was low and so there was not probably a strong depolymerization of the chains of amylose and amylopectin. 
Amorphous structure of amylopectin facilitates the oxidator into the starch molecules. Oxidation process occurs in amorphous area, shown by no changes in the pattern of X-ray and its intensity on the oxidation products (Kuakpetoon and Wang, 2001). The differences in amylose contents of oxidized cassava starch are influenced by UV-C intensity, oxidation time, dan hydrogen peroxide concentration. Fermentation and sun drying of cassava starch can increase amylose content, as resulted in the rising of amylose content of sun-dried fermented cassava starch than native cassava starch.

\section{Swelling power}

Based on study result, the swelling power of oxidized cassava starch is lower than its native (Table 3 ). The decreasing of swelling power might be due to photocrosslinking during oxidation (Wang and Wang, 2003; Lorlowhakarn and Naivikul, 2005). This evidence possibly related to crystallization of amylose and amylopectin in the starch granule as reported in previous studies (Vatanasuchart et al., 2005; Wang and Wang, 2001). The reduction in the swelling power after oxidation may be attributed to structural disintegration within the granules of the starch during the process of modification (Lawal, 2004).

\section{Solubility}

The solubility is a consequence of the leaching of amylose which leads to decreasing of the solubility as the time increased, indicate the increasingof the interactions between amylose and amylopectin molecules, or between amylopectin molecules (forming a more stable structure), impending to the leaching out of the granules (Gomes et al., 2005). The solubility of oxidized cassava starch is greater than its native (Table 3 ) which caused by the depolymerization of starch structure and hydrogen bonds which weakness in the oxidized starch. The weakening of the hydrogen bonds makes oxidator easier to penetrate into starch granules, result to form some short chain amylose fraction which is soluble in liquid. All independent variables in this study affect the solubility of oxidized cassava starch.

Sun-dried fermented cassava starch has a higher solubility than native cassava starch. The manufacture of this kind of cassava starch similiar with the manufacture of polvilho azedo. The polvilho azedo is a hydrolyzed starch by fermentation process, resulting to weaker bonds, which facilitated the water penetration in the amorphous zones and the leaching of amylose from the granules during the heating process, mainly close to its gelatinization temperature (Camargo et al., 1988).

\section{Optimization of oxidation process}

Equations relationships between the frying expansion (Y) with UV-C intensity $\left(\mathrm{X}_{1}\right)$, oxidation time $\left(\mathrm{X}_{2}\right)$, and hydrogen peroxide concentration $\left(\mathrm{X}_{3}\right)$ are:

$$
\begin{aligned}
& Y=-308,595+18,441 X_{1}+256,106 X_{2}-6,184 X_{3}-0,177 \\
& X_{1}^{2}-41,110 X_{2}^{2}+12,640 X_{3}^{2}-1,354 X_{1} X_{2}-0,958 X_{1} \\
& X_{3}-6,250 X_{2} X_{3}
\end{aligned}
$$

Table 3

Amylose content, swelling power, and solubility of oven-dried cassava starch oxidized with hydrogen peroxide and UV-C irradiation

\begin{tabular}{lllllll}
\hline Treatment & $\mathrm{I}$ (watt) & $\mathrm{t}$ (minute) & $\begin{array}{l}\mathrm{C}(\mathrm{g} / 100 \\
\mathrm{g})\end{array}$ & $\begin{array}{l}\text { Amylose } \\
\text { content }(\%)\end{array}$ & $\begin{array}{l}\text { Swelling } \\
\text { power }(\mathrm{g} / \mathrm{g})\end{array}$ & $\begin{array}{l}\text { Solubility } \\
(\%)\end{array}$ \\
\hline 1 & 20 & 1 & 2 & 30.24 & 0.456 & 2.22 \\
2 & 60 & 1 & 2 & 30.35 & 0.289 & 2.16 \\
3 & 20 & 3 & 2 & 32.98 & 0.529 & 2.06 \\
4 & 60 & 3 & 2 & 31.21 & 0.580 & 2.16 \\
5 & 20 & 2 & 1 & 32.28 & 0.603 & 2.08 \\
6 & 60 & 2 & 1 & 34.18 & 0.419 & 2.40 \\
7 & 20 & 2 & 3 & 32.61 & 0.379 & 2.09 \\
8 & 60 & 2 & 3 & 35.59 & 0.445 & 2.08 \\
9 & 40 & 1 & 1 & 32.47 & 0.490 & 2.23 \\
10 & 40 & 3 & 1 & 34.21 & 0.301 & 2.07 \\
11 & 40 & 1 & 3 & 31.84 & 0.388 & 2.02 \\
12 & 40 & 3 & 3 & 33.37 & 0.401 & 2.01 \\
13 & 40 & 2 & 2 & 33.73 & 0.370 & 2.24 \\
14 & 40 & 2 & 2 & 33.61 & 0.369 & 2.13 \\
15 & 40 & 2 & 2 & 33.32 & 0.365 & 2.24 \\
Native cassava starch & & & 29.67 & 1.453 & 1.79 \\
Sun-dried fermented cassava starch & & 33.33 & 1.102 & 1.91 \\
\hline
\end{tabular}

From the calculation results, optimum condition on oxidizedoven-dried cassava starch with $\mathrm{H}_{2} \mathrm{O}_{2}$ and catalyzed by UV-C irradiation got on UV-C intensity40 watt, oxidation time 2,281 minutes, and hydrogen peroxide concentration $1 \%$ with frying expansion $347,26 \%$ and desirability 0,63738 . Contour curve of frying expansion of sun-dried cassava starch oxidized with hydrogen peroxide and UV-C irradiation are shown in Figure 1. 


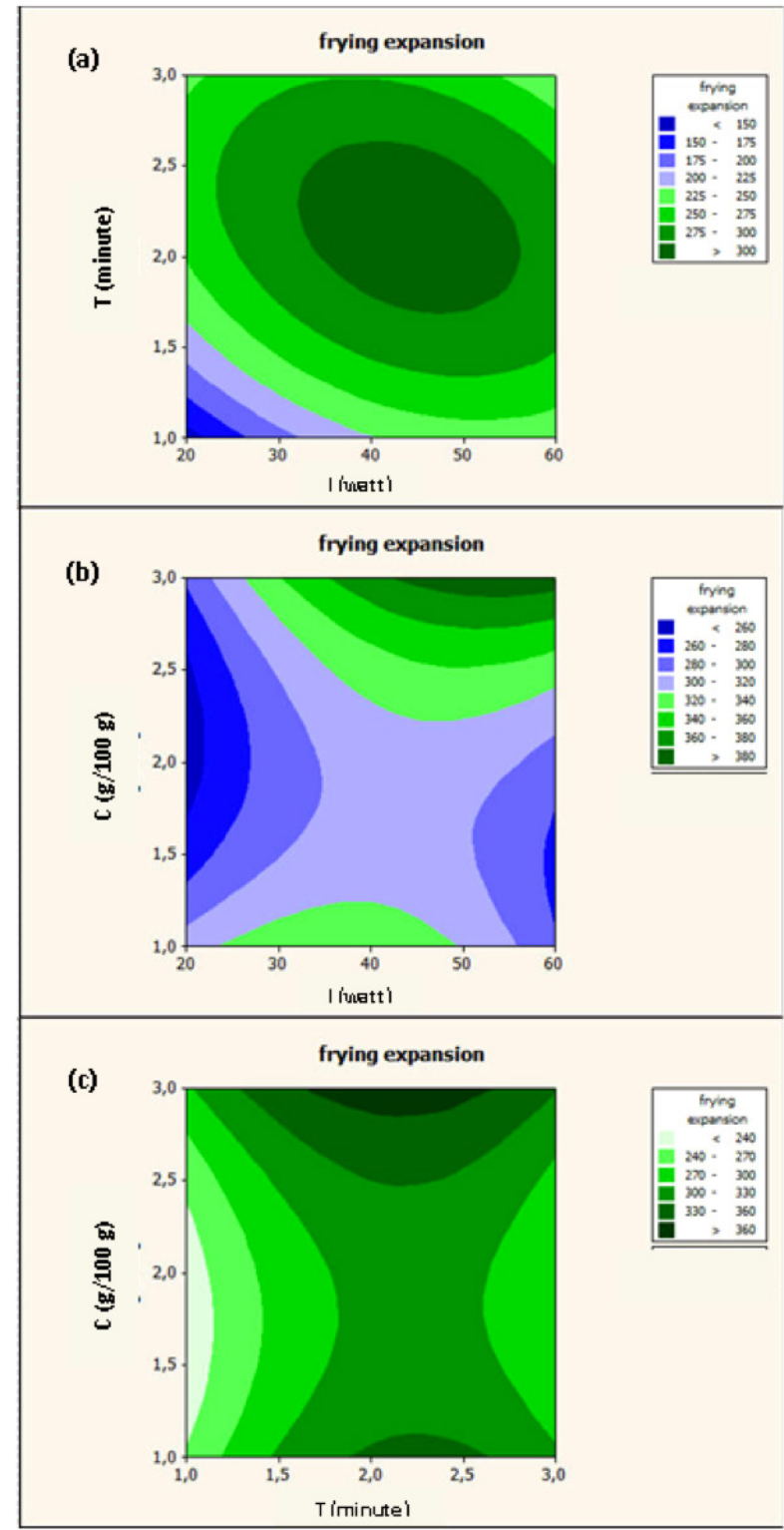

Figure 1. Contour curve of frying expansion of sun-dried cassava starch oxidized with hydrogen peroxide and UV-C irradiation as a function of UV-C intensity and time of oxidation (a), UV-C intensity and concentration of hydrogen peroxide (b), time of oxidation and concentration of hydrogen peroxide (c)

\section{CONCLUSION}

Oxidation of cassava starch with $\mathrm{H}_{2} \mathrm{O}_{2}$ and catalyzed by UV-C produced a greater number of the frying expansion, carbonyl content, carboxyl content, amylose content, solubility, greater than cassava starch without oxidation (native), and havelower swelling power. The optimum condition on oven-dried cassava starch oxidation with $\mathrm{H}_{2} \mathrm{O}_{2}$ and catalyzed by UV-C got on UV-C intensity 40 watt, oxidation time 2,281 minutes, and hydrogen peroxide concentration $1 \%$ with frying expansion $347,26 \%$.

\section{REFERENCES}

AOAC. 1984. Official Methods of Analysis. Ed 14 ${ }^{\text {th }}$. Association of Official Analytical Chemists, Washington, USA.

Berski, W., Ptaszek, A., Ptaszek, P., Ziobro, R., Kowalski, G., Grzesik, M. and Achremowicz, B. 2011. Pasting and rheological properties of oat starch and its derivatives.
Carbohydrate Polymers. 83: 665-671.

Bertolini, A.C., Mestres, C., dan Colonna, P. 2000. Rheological properties of acidified and UV-irradiated starch. Starch/Starke. 52:340-344.

Camargo, C., Colon, P., Buleon, A., andMolard, D. R. 1988. Functional properties of sour cassava (Manihotutilissima) starch: polvilhoazedo. Journal of the Science of Food and Agriculture.45: 273-289.

Demiate, I.M., Dupuy, N., Huvenne, J. P., Cereda, M. P., and Wosiacki, G. 2000. Relationship between baking behavior of modified cassava starches and starch chemical structure determined by FTIR spectroscopy. Carbohydrate Polymer. 42:149-158.

Dias, A.R.G., Zavareze, E.R., Helbig, E., de Moura, F.A., Vargas, C.G. andCiacco, C.F. 2011. Oxidation of fermented cassava starch using hydrogen peroxide. Carbohydrate Polymers. 86:185- 191 .

Fiedorowicz, M., Tomasik, P., Cracow, You, S., and Lim S. 1999. Molecular distribution and pasting properties of UV irradiated corn starches. Starke. 51: 126-131.

Fortuna, T., Juszczak, L., Pietrzyk, S. and Wróbel, M. 2002. Physico-chemical properties of oxidised starches of different origin. Polish Journal of Food and Nutrition Sciences. 11/52: 21-27.

Gomes, A.M.M., da Silva, C.E.M., and Ricardo, N.M.P.S, 2005. Effects of annealing on the physicochemical properties of fermented cassava starch (polvilhoazedo). Carbohydrate Polymers. 60:1-6.

Kainuma, K., Odat, T., and Cuzuki, S. 1967. Study of starch phosphates monoesters. Journal of Technology Society Starch. 14:24-28.

Kuakpetoon, D., and Wang, Y.J. 2001.Characterization of different starches oxidized by hypochlorite.Starch/Stärke.53:211-218.

Lawal, O. S. 2004. Composition, physicochemical properties and retrogradation characteristics of native, oxidized, acetylated and acid-thinned new cocoyam (Xanthosoma sagittifolium) starch. Food Chemistry. 87:205-218.

Leach, H.W., Mc Cowen, L.D., \&Schoch, T .J. 1959. Structure of the starch granules. In: swelling and solubility patterns of various starches. Cereal Chemistry. 36:534-544.

Lorlowhakarn, K. and Naivikul, O. 2005. Modification of rice flour by UV irradiation to improve rice noodle quality. Proceeding The $3^{\text {rd }}$ Conference of Starch Technology.

Nee, T. S. 1996. Basic principles in photomedicine. In Manual for Workshop in Photodermatology. The 12th Regional Conference of Dermatology, May 11. Pattaya, Thailand.

Parovuori, P., Hamunen, A., Forssell, P., Autio, K. and Poutanen, K. 1995. Oxidationofpotatostarchbyhydrogenperoxide.Starch/ Starke.47:19-23.

Pereira, J.M, Evangelho, J.A, Moura, F.A., Gutkoski, L.C., Zavareze, E.R. and Dias, A.R.G. 2017. Crystallinity, thermal and gel properties of oat starch oxidized using hydrogen peroxide. International Food Research Journal. 24(4): 15451552

Plata-Oviedo, M. and Camargo, C. 1998. Effect of acid treatments and drying processes on physicho-chemical functional properties of cassava starch. Journal of the Science of Food and Agriculture. 77:103-108.

Sangseethong, K., Termvejsayanon, N., andSriroth, K. 2010. Characterization of physicochemical properties of hypochlorite and peroxide-oxidized cassava starches.Carbohydrate Polymers. 82:446-453.

Schmorak, M. L. 1963. The chemical and physicochemical properties of wheat starch mildly oxidized with alkaline sodium hypochlorite. Journal Polymers Science: Part A1:260-2620.

Smith, R. J. 1967. Production and used of hypochlorite oxidized starches (Vol. II). In "Starch chemistry and Technology" ed. R. L. Whistler, \& E. F. Paschall, pp. 620-625. Academic Press. New York

Takizawa, F. F., Silva, G. O., Konkel, F. E., \& Demiate, I. M. 2004. Characterization of tropical starches modified with 
potassium permanganate and lactic acid. Brazilian Archives of Biology and Technology. 47:921-931.

Tavares, A.C.K. Zavareze, E., E. Zanatta, E.R..Helbig, and Dias, A.R.G. 2010. The effect of acid and oxidative modification on the expansion properties of rice flour with varying levels of amylose. LWT-Food Science and Technology.43:1213-1219.

Vatanasuchart, N., Naivikul, O., Charoenrein, S., and Sriroth, K. 2005. Molecular properties of cassava starch modified with different UV irradiations to enhance baking expansion. Carbohydrate Polymers. 61:80-87.

Wang, L. and Wang, Y.T. 2001. Structures and physico-chemical properties of acid-thinned corn, potato and rice starches. Starch/Stärke. 53:570-576.

Wang, Y.J. and Wang, L. 2003. Physicochemical properties of common and waxy corn starch oxidized by different level of sodium hypochlorite. Carbohydrate Polymers. 52:207-217. 